\title{
Manual of Recommendations for the Diagnosis, Therapy, and Follow-Up of Patients with Breast Cancer of the Tumor Center Munich - a Regional Hands-On Publication
}

\author{
Wolfgang Janni, for the Projektgruppe Mammakarzinom TZM Munich* \\ Frauenklinik Innenstadt, LMU München, Germany
}

\section{Keywords}

Breast cancer: prognosis, recurrence - Chemotherapy . Endocrine therapy · Radiotherapy · Recommendations . Guidelines

\section{Summary}

The revised 11th edition of the Manual of Recommendations for the Diagnosis, Therapy, and Follow-Up of Patients with Breast Cancer of the publications series of the Tumor Center Munich (Tumorzentrum München, TZM) is an excellent example of a regional hands-on publication which, while based on national and international guidelines, does not replace these. By virtue of countless additions and revisions in the course of 10 editions, the 'blue tumor manual for breast cancer' has matured into a hands-on reference work which throughout Germany has found its place on the desks of physicians, and has thus gained a reputation reaching far beyond the TZM. The reputation of this manual is on the one hand founded on the professional competence of the individual authors and project group members. The great strength of the project group, however, surely lies in the broad spectrum of expertise of more than 180 experts of all kinds of specialties, whose continuing interdisciplinary exchange in the course of the present revision has again led to a result which is arousing interest far beyond Munich. This article summarizes some of the TZM project group's own positions on data collection, prevention, adjuvant systemic therapy, and follow-up treatment in an exemplary fashion.

\author{
Schlüsselwörter \\ Brustkrebs: Prognose, Rezidiv · Chemotherapie · \\ Endokrine Therapie - Strahlentherapie - Empfehlungen · \\ Leitlinien
}

\section{Zusammenfassung}

Die überarbeitete 11. Auflage des Manuals mit Empfehlungen zur Diagnostik, Therapie und Nachsorge bei Patientinnen mit Mammakarzinom aus der Schriftenreihe des Tumorzentrums München (TZM) ist ein exzellentes Beispiel für eine regionale Handlungsanweisung für die tägliche Praxis, die zwar auf den nationalen und internationalen Leitlinien basiert, diese aber nicht ersetzt. Durch unzählige Ergänzungen und Überarbeitungen innerhalb von 10 Auflagen ist das "blaue Tumormanual Mammakarzinom» zu einem praxisnahen Nachschlagewerk gereift, das bundesweit auf den Schreibtischen von Ärztinnen und Ärzten zu finden ist und damit eine Bedeutung erlangt hat, die weit über das Verbreitungsgebiet des TZM hinausgeht. Die Reputation dieses Manuals gründet zum einen auf der Fachkompetenz der einzelnen AutorInnen und Projektgruppenmitglieder. Die große Stärke der Projektgruppe liegt aber sicherlich im breiten Spektrum der Expertise von über 180 ExpertInnen aller erdenklichen Fachdisziplinen, deren interdisziplinärer Austausch auch bei der aktuellen Überarbeitung wieder zu einem weit über München hinaus beachteten Ergebnis geführt hat. Dieser Artikel fasst einige eigene Standpunkte der Projektgruppe des TZM zur Datenerfassung, zur Prävention, zur adjuvanten Systemtherapie und zur Nachsorge exemplarisch zusammen.

$\overline{\text { *Members are listed in }}$ the appendix of this article.

\begin{tabular}{ll}
\hline KARGER & ๑ 2008 S. Karger GmbH, Freiburg \\
Fax +497614520714 & Accessible online at: \\
$\begin{array}{l}\text { E-mail Information@Karger.de } \\
\text { www.karger.com }\end{array}$ & www.karger.com/brc
\end{tabular}




\section{Introduction}

The revised 11th edition of the Manual of Recommendations for the Diagnosis, Therapy, and Follow-Up of Patients with Breast Cancer of the publications series of the Tumor Center Munich (Tumorzentrum München, TZM) [1] is an excellent example of a regional hands-on publication which, while based on national and international guidelines, does not replace these. By virtue of countless additions and revisions in the course of 10 editions, the 'blue tumor manual for breast cancer' has matured into a hands-on reference work which throughout Germany has found its place on the desks of physicians, and has thus gained a reputation reaching far beyond the TZM. This article summarizes some of the TZM project group's own positions on data collection, prevention, adjuvant systemic therapy, and follow-up treatment in an exemplary fashion.

\section{Position on Data Collection: Epidemiological Data from the Munich Cancer Registry}

The Munich Cancer Registry (Tumor-Register München, TRM) [1] collects clinical data from the Munich area in exemplary fashion, and evaluates these at regular intervals in the sense of a modern 'benchmarking' for medical quality control. The TRM's catchment area has repeatedly been enlarged since its foundation in 1978. Starting from the Munich municipal area, documentation was continually extended to the surrounding administrative districts. As a result, there is the 'old catchment area' of 1978 with 2.3 million inhabitants from Munich city and the administrative districts of Dachau, Ebersberg, Erding, Freising, Fürstenfeldbruck, München-Land (Greater Munich Area), and Starnberg. About 10 years later (i.e. around 1988), complete coverage of the population in this area with regard to breast cancer patients was by and large achieved. Since 1994, all pathological findings in the region are fully transmitted to the TRM. Some up-to-date epidemiological parameters for Germany are displayed in table 1 . The results and estimates have been compiled from various sources. In 1998, the Law on the Implementation of the Cancer Registry Law (Gesetz zur Ausführung des Krebsregistergesetzes, AGKRG) came into effect. In the AGKRG, processing of death certificates by the TRM was for the first time made legally binding, starting 1 January 1998. This regulation was also adopted in the Bavarian Cancer Registry Law (Bayerisches Krebsregistergesetz, BayKRG). In the BayKRG, which was passed in the year 2000, region-wide registration of cancer cases in all of Bavaria beginning with the year 2002 was enacted, which for the TRM led to an expansion of the catchment area so that it now covers 3.84 million inhabitants as opposed to 2.3 million. The new catchment area includes, in addition to the previous area, the administrative districts of Weilheim-Schongau, Garmisch-Partenkirchen, Bad Tölz-Wolf-
Table 1. Basic epidemiological figures for Germany (Engel et al. [5])

\begin{tabular}{|c|c|c|}
\hline \multicolumn{3}{|l|}{ Incidence } \\
\hline Annual incidence in Germany, \% & 2002 & 26.8 \\
\hline Absolute incidence $^{\mathrm{a}}$ (per 100,000$)$ & 2002 & 126.8 \\
\hline \multicolumn{3}{|l|}{ Proportion of all new cancer cases ${ }^{a}$} \\
\hline$($ per 100,000$)$ & $1998-2002^{\mathrm{e}}$ & 73.6 \\
\hline Raw incidence $(\mathrm{RKI})^{\mathrm{b}}$ (per 100,000) & $1998-2002^{\mathrm{e}}$ & 154.7 \\
\hline \multicolumn{3}{|l|}{ Incidence (RKI) world standard (ASR) ${ }^{b}$} \\
\hline$($ per 100,000$)$ & $1998-2004^{\mathrm{e}}$ & 86.7 \\
\hline Raw incidence $(T R M)^{c}$ & $1998-2004^{\mathrm{e}}$ & \\
\hline Incidence (TRM) world standard $(\mathrm{ASR})^{\mathrm{c}}$ & $1998-2004^{e}$ & \\
\hline \multicolumn{3}{|l|}{ Age at onset, years } \\
\hline Average & 1998-2005 & 63.4 \\
\hline $10 \%$ younger than $/ 10 \%$ older than ${ }^{c}$ & $1998-2005$ & $44.7 / 82.7$ \\
\hline \multicolumn{3}{|c|}{ Average survival period (cancer-related death), years } \\
\hline M0 $(\mathrm{TRM})^{\mathrm{c}}$ & 1978-2005 & 6.4 \\
\hline All, including M1 (TRM) ${ }^{\mathrm{c}}$ & 1978-2005 & 5.6 \\
\hline \multicolumn{3}{|l|}{ Survival rate, $\%$} \\
\hline 5-year (overall/relative) ${ }^{\mathrm{c}}$ & 1998-2005 & $78.4 / 85.4$ \\
\hline 10 -year $(\text { overall/relative })^{\mathrm{c}}$ & 1978-2005 & $59.8 / 70.6$ \\
\hline 15 -year (overall/relative) ${ }^{\mathrm{c}}$ & $1978-2005$ & $46.6 / 60.4$ \\
\hline \multicolumn{3}{|l|}{ Deaths } \\
\hline Deaths from breast cancer in Germany, $\mathrm{n}$ & 2005 & 17,455 \\
\hline Deaths due to cancer in Germany ${ }^{\mathrm{d}}, \%$ & 2005 & 17.6 \\
\hline
\end{tabular}

RKI = Robert Koch Institute; ASR = age standardized rate (here: world standard); TRM = Tumor-Register München (Munich Cancer Registry). aSociety of Epidemiologic Cancer Registries in Germany (Gesellschaft epidemiologischer Krebsregister in Deutschland e.V., GeKiD) in cooperation with the RKI [6]. The new cases are an estimate for the year 2002.

${ }^{\mathrm{b}}$ The raw incidence indicates the number of new cases per 100,000 women occurring in a year. Here, the averaged values from 1998 to 2002, which is the latest year currently available, are indicated [3].

cThe incidences (raw, world standard) are averaged values of the annual cohorts of 1998-2004 in the TRM catchment area: Munich and bordering administrative districts, from 2002 additionally administrative districts from almost all of Upper Bavaria. The different values of age at onset are averaged values of the 1998-2005 annual cohorts. Survival probabilities have been determined for the 5-year survival rates from the annual disease cohorts from 1998 to 2005, for the 10- and 15-year survival rates from annual cohorts from 1978 to 2005. All deaths are included in observed or overall survival, while relative survival is an estimate for tumor-specific survival. Relative survival is calculated by dividing observed (overall) survival by expected survival and thus estimating tumor-specific survival [4]. Expected survival describes the survival rate of a normal population cohort of identical composition with respect to age and gender.

${ }^{\mathrm{d}}$ Federal Office of Statistics (Statistisches Bundesamt): causes of death in Germany 2005 [2].

ratshausen, Miesbach, Rosenheim, Berchtesgaden, Traunstein, Altötting, Mühldorf am Inn, and Landshut. The end-of-2005 amendment to the BayKRG stipulates a re-organization of the catchment areas with effect from 1 January 2007 insofar as the entire government district of Upper Bavaria as well as the administrative districts of Landshut and Greater Landshut Region are to be part of the TRM catchment area. The number of inhabitants thus rises to 4.4 million. Under www. tumorregister-muenchen.de (see also www.krebsinfo.de), data on incidence and mortality as well as tumor-specific evaluations with basic statistics, survival analyses, and special analyses are 


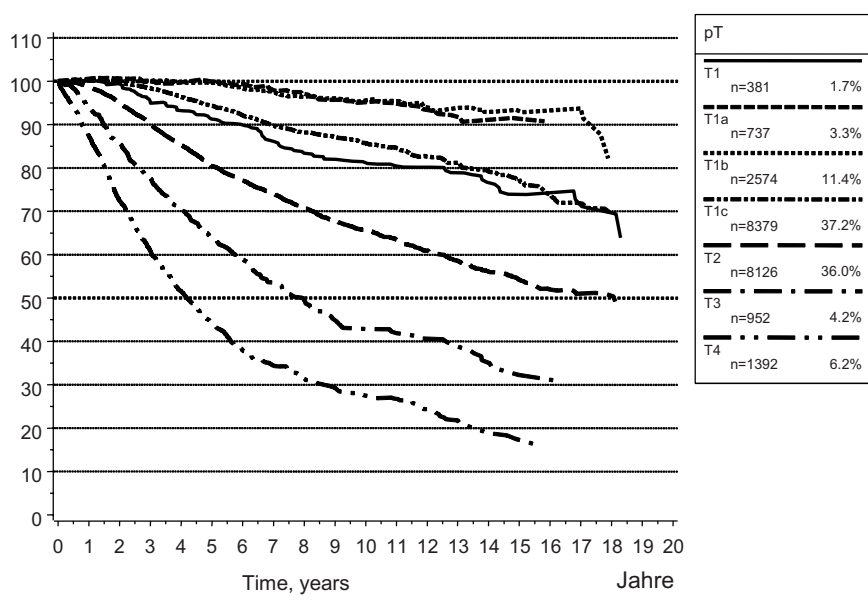

Fig. 1. Munich Cancer Registry: breast cancer, relative survival in relation to $\mathrm{pT}(\mathrm{n}=22,541)$; relative survival is an estimate for tumor-specific survival (Engel et al. [5]).

made available online. Furthermore, annual reports as well as further information on the TRM are to be found here (table 2, fig. 1).

\section{Position on Prevention}

The TZM breast cancer project group has developed practical recommendations for affected patients on the basis of existing data from prospective randomized studies (tables 3 and 4). Prevention of diseases with high epidemiological frequency has increasingly moved into the focus of health policy considerations and become part of physicians' professional activities. All in all, increasing efforts toward early diagnosis and prevention on the part of doctors and also of the financing institutions have become evident over the course of the last years. Education on preventive measures, first and foremost of women at high risk, has been intensified and is slowly finding its place in practical clinical implementations (WHO Global Strategy on Diet and Physical Activity: key policy recommendations; www.brustkrebsvorbeugen.de).

The promising results of the present breast cancer prevention trials show that prevention is possible either by avoiding carcinogenesis, or through a form of early therapy. Future trial results will show which substance in practice is most effective and has the least adverse side effects. The dilemma of having to treat a great number of healthy women in order to prevent disease occurrence in a few, will, however, remain unchanged. Selective prevention specifically targeting individuals is, as of yet, not possible. The influence of breast cancer prevention on overall survival has not yet been demonstrated. It follows that, notwithstanding all positive intentions, a specific appraisal of risks and benefits with respect to the individual case in interdisciplinary cooperation, following extensive patient education, must be ensured. Drug prevention as well as surgi-
Table 2. Proportion of classical prognostic factors in relation to pT category for the annual cohorts from 1998 to $2004(\mathrm{n}=13,091)$ of the Munich Cancer Registry (Engel et al. [5])

\begin{tabular}{|c|c|c|c|c|c|c|}
\hline $\begin{array}{l}\text { pT } \\
\text { category }\end{array}$ & $\begin{array}{l}\text { Patients, } \\
\%\end{array}$ & $\begin{array}{l}\text { Average } \\
\text { age, years }\end{array}$ & $\begin{array}{l}\mathrm{pN} \\
\text { positive, } \\
\%\end{array}$ & G3, \% & $\begin{array}{l}\text { Receptor- } \\
\text { negative, } \\
\%\end{array}$ & $\begin{array}{l}\text { Primary } \\
\text { M1, \% }\end{array}$ \\
\hline pTis & 6.3 & 58.8 & 0 & - & 21.4 & 0 \\
\hline pT1 & 52.4 & 59.6 & 24.9 & 23.6 & 11.5 & 1.3 \\
\hline pT1a & 2.9 & 58.5 & 9.7 & 18.2 & 14.1 & 0.8 \\
\hline pT1b & 12.0 & 59.7 & 15.5 & 14.5 & 9.8 & 0.9 \\
\hline pT1c & 37.5 & 59.8 & 29.5 & 26.5 & 11.5 & 1.5 \\
\hline pT2 & 32.5 & 62.9 & 49.7 & 44.9 & 16.3 & 4.1 \\
\hline pT3 & 3.8 & 64.5 & 68.2 & 52.0 & 20.4 & 9.2 \\
\hline pT4 & 5.0 & 72.2 & 71.3 & 54.1 & 14.5 & 25.6 \\
\hline Overall & 100 & 63.4 & 35.3 & 33.8 & 14.1 & 3.7 \\
\hline
\end{tabular}

cal prevention should only be carried out under clinical trial conditions at well-established centers. At present, the IBIS II trial is open for postmenopausal women in Germany with increased risk of breast cancer. Comprehensive information for physicians involved in the care of such patients and for women seeking advice are available under $w w w$. brustkrebsvorbeugen.de.

\section{Position on Adjuvant Therapy Recommendations}

With the exception of patients with cancer in the earliest stages (so called low-risk group according to St. Gallen 2007), adjuvant systemic therapy is, in principle, indicated.

\section{Endocrine Therapy}

Endocrine therapy is always indicated in hormone-sensitive (hormone receptor-positive) tumors, but side effects should also be taken into consideration in tumors with doubtful hormone sensitivity. Endocrine therapy can be dispensed within the low-risk group, as a decisive advantage in terms of life expectancy is not to be expected. In the final analysis, even the low rate of side effects can, for example, lead to additional therapy-related deaths at a similar rate as tumor-related deaths would be prevented. Endocrine therapy in this group serves above all to prevent contralateral cancer growths and local recurrence. Endocrine therapy should be started after concluding chemotherapy if this is indicated, it can, however, be initiated either simultaneously with radiotherapy or after conclusion of radiotherapy. Menopause status is the essential distinguishing criterion for the type of endocrine therapy.

\section{Postmenopause}

According to the present state of knowledge, there are 2 options in the postmenopause: the hitherto accepted standard tamoxifen 
Table 3. Summary and recommendations on breast cancer prevention with tamoxifen (Wolf et al. [6])
General recommendation

\section{Treatment goal}

Greatest clinical benefit with less adverse side effects

Tamoxifen in combination with hormone replacement therapy (HRT)

Tamoxifen in combination with or followed by other drugs with potential preventive effect Proven effect on overall survival

Estimated overall survival and cost-benefit analysis in high-risk groups

Comment women with risk of breast cancer $>1.66 \%$ in the next 5 years

(20 $\mathrm{mg} /$ day for 5 years) for risk reduction

reduction of short term risk of developing breast cancer

premenopausal, hysterectomized, and younger women (lower risk of thrombosis)

not recommended outside of clinical studies due to unreliable data regarding a possible increase in breast cancer incidence and long term adverse effects; the European studies (Veronesi, Powles) permitted HRT - with opposite effects; in the HOT trial (Italy; Decensi), low-dose tamoxifen (5 mg) is combined with HRT

no data available

no data available (has up to now not been defined as study end point); the IBIS I trial shows increased mortality due to other causes of death in the tamoxifen arm with respect to the comparison arm according to model calculations in the group with atypical ductal hyperplasia, an increase in life expectancy of 202/89/45 days is expected when tamoxifen treatment is begun at age 35/50/60 respectively; greatest effectiveness is to be expected with a risk calculated according to Gail $>5 \%$, in the group with lobular carcinoma in situ or more than 2 first-degree relatives with breast cancer, if treatment is started before the age of 50; in this case, cost would be in balance with benefit

tamoxifen treatment recommendations should be voiced in the context of the overall process of counseling women with increased risk of breast cancer while taking into account benefit/risk considerations; the drug is approved for the indication of breast cancer prevention exclusively in the USA; in Germany, preventive drug therapy is to be recommended only under clinical trial conditions
Table 4. Summary and recommendations on breast cancer prevention: further drugs or groups of drugs (Wolf et al. [6])

\section{Drug/group of drugs}

Aromatase inhibitors

Selective estrogen receptor modulator (SERM) raloxifene Retinoids COX-2 inhibitors

Beta-carotene

\author{
Current recommendations \\ only under trial conditions: anastrozol presently tested against placebo in post \\ menopausal women with (moderately to strongly) increased risk of breast cancer in \\ Europe and Australia/New Zealand \\ to date only tested under trial conditions against tamoxifen (results of STAR, MORE, \\ CORE trials available) \\ only under trial conditions \\ only under trial conditions (at present not to be recommended in general) \\ not recommended, tested as exclusive therapy or in combination without proof of \\ preventive effect
}

(20 mg/day), and application of an aromatase inhibitor. According to guidelines, almost every postmenopausal patient should be offered an aromatase inhibitor. The optimal therapy scheme when initiating endocrine therapy has not yet been finally clarified: besides up-front therapy with an aromatase inhibitor, sequential therapy with tamoxifen for 2-3 years followed by an aromatase inhibitor is also evidence-based. Therapy exclusively with tamoxifen is an option for low-risk patients or when contraindications apply. Duration of adjuvant endocrine therapy is 5 years in all. After completing a 5-year course of tamoxifen therapy, extended adjuvant therapy with an aromatase inhibitor can be useful, particularly in nodal-positive patients.

\section{Premenopause}

In women who will not receive chemotherapy (see below), a combination of gonadotropin-releasing hormone $(\mathrm{GnRH})$ analogues (or other forms of ovarian ablation) and tamoxifen should be applied. When chemotherapy is applied, endocrine standard therapy is sequential therapy with tamoxifen ( $20 \mathrm{mg}$ /day over 5 years). Following chemotherapy, additional therapy with GnRH analogues is not standard, but may be considered upon completing chemotherapy in very young women under the age of 40 or when premenopausal hormone levels persist. Therapy with GnRH analogues should be carried out for at least 2 years ( 5 years at most). Oncological data on the effectiveness of aromatase inhibitors in premenopause are presently not yet available. Exclusive administration of aromatase inhibitors in premenopausal patients is contraindicated. If, in well justified individual cases (e.g. drug intolerance), therapy is to be switched from tamoxifen to an aromatase inhibitor, or if a hitherto amenorrheic perimenopausal patient reverts to premenopausal conditions under therapy with aromatase inhibitors, additional application of GnRH analogues is mandatory. 


\section{Chemotherapy}

\section{Indication}

Evidence from data of randomized studies on adjuvant chemotherapy mostly includes patients under 70 years of age only. More recent studies often no longer have an age limit by date of birth but rather use biological age and comorbidities as orientation criteria. For patients over 65 years of age, further trials are presently being conducted (e.g. ICE) to assess the value of adjuvant chemotherapy in elderly patients. Chemotherapy is generally considered indicated in receptornegative tumors.

Patients with the following indications should in principle be offered chemotherapy (no chemotherapy only on grounds of clear contraindications or refusal): i) axillary lymph nodes affected; ii) doubtful hormone sensitivity if the tumor does not belong to the low-risk category; iii) age under 35 years (in specific cases also under 40).

Chemotherapy should be offered liberally and be carefully discussed with the patient when the following conditions apply: i) lymph nodes affected, no unfavorable tumor biology, good hormone sensitivity and age over 60 years; ii) nodal-negative patients with unfavorable tumor biology (e.g. G3, invasion of blood vessels, HER2 overexpression or increased proteolytic factors uPA or PAI-1); iii) premenopausal women whose lymph nodes are not affected and who do not belong to the 'low risk group'. Chemotherapy may be offered to patients in the following situation: nodal-negative postmenopausal patients without unfavorable tumor biology who do not belong to the low-risk group.

Taking into account the above mentioned cases, chemotherapy can be abstained from in the following situations: i) larger G1 tumors $(2-5 \mathrm{~cm})$ with negative lymph nodes and favorable tumor biology (hormone-sensitive, no blood vessel invasion, no HER2 overexpression, tubular histology, low uPA/PAI-1), especially if the clinical course points to a long disease history (protracted tumor with slow kinetics); ii) G2 tumors (1-2 cm) with favorable auxiliary criteria (see above). No chemotherapy is indicated in cases belonging to the low-risk group according to St. Gallen 2007.

\section{Trastuzumab}

Adjuvant 1-year trastuzumab therapy following primary systemic or adjuvant chemotherapy is standard in HER2-positive breast cancer (HER2 3+ or fluorescent in situ hybridization (FISH)-positive). It is approved regardless of age, nodal status, or time elapsed since primary surgery. Indication should be assessed independent of nodal status or age of the patient, provided there is no contraindication to the planned therapy. According to the present state of knowledge, therapy can be started together with the taxane chemotherapy or carried through completely after chemotherapy.

\section{Off-Label Use}

On the basis of experiences with trastuzumab, the question of off-label use repeatedly arises in adjuvant therapy when therapy procedures substantiated by significant phase III study results and recommended in guidelines have not yet been approved. The following procedure is recommended for physicians planning such therapy: i) approaching an interdisciplinary tumor consultation service as is run by most larger clinics today; ii) alternatively, obtaining a second (or third if necessary) opinion from colleagues with experience, especially in adjuvant therapy studies, in order to have the indication confirmed by several physicians; iii) where necessary, conferring with the respective health insurance to seek confirmation that costs will be met and letting the patient fetch such confirmation from her health insurance. According to experienced lawyers, it is controversial whether the physician should apply for such confirmation himself, as he would find himself in a dilemma in the case of refusal: by his application he would have shown that despite the fact that it is not officially approved, he considers the therapy to be indicated/necessary from a medical point of view so that failure to implement it could even represent medical malpractice. Failure on the part of health insurances to pay for a particular therapy, however, does not absolve the physician from his duty to provide appropriate, medically indicated therapy (in analogy to emergency therapy for uninsured persons). Off-label use is, according to the current jurisdiction by the Federal Social Court, justified and may be refunded by health insurances if it is a case of a potentially life-threatening disease, if data from large phase III studies are available, or if there are no appropriate alternative therapy strategies available.

\section{Position on Follow-Up Treatment}

The TZM's breast cancer project group, while recognizing the (insecure) evidence status, acknowledges the validity of the official follow-up treatment guidelines of the German Cancer Society (Deutsche Krebs-Gesellschaft, DKG) and the American Society of Clinical Oncology (ASCO). The project group does, however, on account of an outdated data basis and practical experiences, see the need for a scientific reassessment of the scope of follow-up therapy with respect to content as well as to scaling of intervals under the conditions of modern diagnostic and therapeutic possibilities.

'Follow-up treatment of cancer patients is a physician's job and is based on up-to-date knowledge of tumor biology.' This is the first sentence of the result statement of a consensus conference which met in February 1995 in Berlin for discussions on content and frequency of follow-up treatment in symptomfree affected persons who had undergone breast cancer surgery. The restrictive follow-up treatment recommendations issued in the 1990s were based on the meta-analyses published in 1994 and 1999, which, using technical diagnostics, had failed 
Table 5. Breast

cancer follow-up: recommendations for symptom-free women after completion of primary breast cancer therapy (Abenhardt et al. [7])

\begin{tabular}{|c|c|c|c|c|}
\hline \multirow[t]{2}{*}{ Clinical follow-up } & \multicolumn{4}{|c|}{ Years following primary therapy } \\
\hline & 2 & 3 & $4+5$ & $6-10$ \\
\hline $\begin{array}{l}\text { History, physical examination, information } \\
\text { Self examination } \\
\text { All other technical examinations including } \\
\text { lab tests and tumor markers (exception } \\
\text { mammography: see below) }\end{array}$ & $\begin{array}{l}\text { every } 3 \text { months } \\
\text { every month } \\
\text { only in case of cli }\end{array}$ & uspi & $\begin{array}{l}\text { nths } \\
\text { ecurrer }\end{array}$ & $\begin{array}{l}\text { every } 12 \text { months } \\
\text { d/or metastases }\end{array}$ \\
\hline \multirow[t]{2}{*}{ Mammograpy $^{\mathrm{a}}$} & \multicolumn{4}{|c|}{ Years following primary therapy } \\
\hline & 2 & 3 & 4 and & wing \\
\hline BCS ipsilateral breast & \multirow{3}{*}{\multicolumn{2}{|c|}{$\begin{array}{l}\text { every } 6 \text { months } \\
\text { every } 12 \text { months } \\
\text { every } 12 \text { months }\end{array}$}} & \multirow{3}{*}{\multicolumn{2}{|c|}{$\begin{array}{l}\text { every } 12 \text { months } \\
\text { every } 12 \text { months } \\
\text { every } 12 \text { months }\end{array}$}} \\
\hline BCS contralateral breast & & & & \\
\hline Mastectomy contralateral breast & & & & \\
\hline
\end{tabular}

af necessary supplemented by sonography in cases of dense corpus mammae, unclear findings in mammography or in order to depict the axilla.

$\mathrm{BCS}=$ Breast conserving surgery. to deliver proof of increased life expectancy despite improved early diagnosis in up to $10 \%$. No more systematic analyses have been carried out or published since then, or could even be implemented due to a lack of willingness on the part of the patients to undergo randomization.

The follow-up recommendations valid since the 5th edition of the TZM manual (1994) are still congruent with the current ASCO guidelines [2], and in the same form also constitute the content of the new evidence based (S3) guideline of the DKG for Germany (table 5). The principle still applies that (apart from mammography and breast sonography) no routine machine-aided diagnostics, including laboratory tests and tumor markers, should be carried out in symptom-free affected persons, as no benefit has been proven for these measures. For follow-up of symptom-free women, detailed history and a thorough physical examination, counseling as well as diagnosis and, if applicable, treatment of therapy-associated side effects is recommended as the primary duty of a physician. Sonography of the operative field and lymphatic drainage can supplement physical examination following breast conserving therapy as well as ablation. Other expert opinions which deviate from these results of systematic evaluation of world literature and, albeit without sufficient evidence, call for an extended follow-up program, have also been publicized. Special tests may become necessary in the course of follow-up when certain drugs (e.g. tamoxifen, aromatase inhibitors, bisphosphonates) are administered. In these cases, regular laboratory tests (especially liver and kidney status, blood sugar, calcium), gynecological examinations and, before beginning tamoxifen therapy and in the event of visual impairment, check ups by an ophthalmologist are to be recommended. Especially after a lengthy tamoxifen therapy, isolated cases of uterine cancer on the basis of endometrial hyperplasia occur. If anthracyclines are administered as pretherapy, the possibility of subsequent cardiomyopathy should be considered (with prescription of echocardiography or multiple-gated acquisition (MUGA) scan), especially in cases of a high cumulative dose. Further rare after-effects are degenerative central nervous system (CNS) diseases with cerebral dysfunction and secondary cancers such as leukemia, lymphomas, or sarcomas in the irradiated area.

An important component of this program is the women's selfobservation and self-examination of the operated region as well as the contralateral breast. Women should be encouraged at every follow-up consultation to seek their doctor's advice immediately in the event of any change or complaint, and not to wait until the next routine consultation. The intensive, personal conversation between the oncologically experienced doctor and his patient, for which no amount of machine-aided diagnostics can ever be a substitute, must also especially take into account the woman's psycho-social situation. Support must be offered as appropriate. This also includes informing the patient on her legal rights to medical and psychological rehabilitation measures, social support (disability certificate, improved exemption from contribution payments, where applicable also nursing care services, household help, family help, self-help groups) as well as to other benefits (physical therapy, supply with prosthesis, advice on underwear, wig). In the present age, with resources scarce and budgets tight, important physical therapy measures in sufficient quantities are not seldom refused with reference to limited budgets because of the danger of regress. In such cases, the oncologist in charge is required, if necessary also by legal means, to ensure provision appropriate to the patient's needs, particularly lymph drainage of sufficient duration and frequency. 


\section{Data on Intensified Follow-Up}

In the past 10-20 years, recommendations for follow-up of patients after primary therapy of localized or regional breast cancer have been published in numerous publications and leaflets. Most of these assumed an empirical, 'programmed' follow-up with a fixed frequency of follow-up consultations and fixed respective content (e.g. bone scan, chest X-ray, abdominal sonography, mammography, and laboratory tests/ tumor markers). Up to this day, there are no data to support an increase in life expectancy linked to early diagnosis and treatment of distant metastases. Three effects could potentially justify intensified follow-up treatment: i) improved survival rate (no evidence to date); ii) increased life expectancy from time of diagnosis (no evidence to date); iii) improved quality of life (no clear evidence to date).

In the study by Roselli et al. [2], which was re-evaluated after 10 years in 1999 (without gaining new insights), 1,243 patients with breast cancer were randomized by 12 Italian centers from 1985 to 1986 . All in all, the risk distribution was rather favorable (57\% postmenopausal, $40.1 \%$ pT1, $46.7 \%$ pT2, $51.5 \%$ $\mathrm{pN} 0,48.5 \%$ with positive hormone receptors). After 5 years, 31 skeletal metastases $(84 / 53)$ as well as 10 lung metastases (28/18) were additionally (and thus earlier) found due to intensified follow-up. In the GIVIO trial [3], a total of 1,441 patients with breast cancer in 32 Italian centers were prospectively randomized between 1986 and 1988. Although the risk distribution was the same in both groups, a significant proportion had favorable risk factors overall (57-59\% postmenopausal, $56 \%$ pN0, 49-51\% pT1, 45-48\% pT2, only 21-22\% negative hormone receptors). After 3 years, metastatic growths could at least be detected additionally (and thus earlier) in 27 patients $(157 / 130$, difference 5\%) due to intensified follow-up (for asymptomatic metastatic growths even $10 \%$ difference). The study was initially designed for a $20 \%$ reduction in tumor-related mortality from 35 to $28 \%$. A mortality of 'only' $18-20 \%$ was, however, found in both groups in the study. Due to earlier diagnosis of metastases, the relapse-free survival of the women in the first study, who received intensive' follow-up, was shorter. A Cochrane meta-analysis [4] published in 2005 found a total of 4 utilizable studies - with the 2 large studies mentioned above taking an absolutely prominent position - and no significant survival benefit through intensified follow-up. However, even in this publication, there is a call for further scientific investigations when new therapy options are available, along with the interesting remark that restrictive follow-up can only be implemented with the consent of sufficiently informed patients.

The main reason for the absence of an effect on the overall survival in these studies relevant to the drawing up of guidelines, however, could be the fact that in the 1980s and 1990s no effective therapy was implemented in order to achieve a significant survival benefit, or that such did not exist at the time. In the last decades, new therapy procedures have been devel- oped that, especially with early and targeted application, can lead to a significant increase in life expectancy in selected collectives, and in individual cases even to long-term remission: i) extension of endocrine therapy options by gonadotropin-releasing hormone $(\mathrm{GnRH})$ analogues, aromatase inhibitors, and new selective estrogen receptor modulators (SERMs); ii) extension of cytostatic therapy options by the taxane substance group an other innovative cytostatic drugs (e.g. capecitabine, gemcitabine, vinorelbin etc.); iii) targeted 'biological' therapy options, especially monoclonal antibodies such as trastuzumab, but also other substance groups, such as small molecules; iv) loco-regional therapy procedures, such as thermoablation, brachytherapy, stereotactic irradiation, and others, which are successful especially in oligometastatic disease. These procedures are bound to be especially effective in tumors of limited expansion with respect to number and volume, i.e. in a relatively early phase of metastatic growth. Sufficient systematic investigations have not been carried out since these therapy options were newly developed, or could not be implemented due to a lack of willingness of the patients to submit to prospective randomization, so that the regular literature research prior to updating and drawing up of national and international guidelines yielded no new knowledge.

The project group is conscious of the fact that in view of the scientific uncertainty summarized here and the doubtlessly existing attitude of high expectancy on the part of patients, there is a broad practice of 'grey follow-up' going on which in future can only be swept aside or substantiated through new, solid scientific data.

\section{Final Recommendations of the TZM Breast Cancer Project Group on Follow-Up Therapy of Breast Cancer}

The official guidelines of ASCO and DKG (S3 guideline) recommend machine-aided diagnostics in breast cancer followup in addition to mammography (on grounds of scientifically founded negative evidence) only in cases with relevant symptoms. The project group acknowledges the validity of the national (S3 guideline of the DKG) and international (ASCO) guidelines, it does, however, in view of weak and outdated data, see the need for a scientific assessment, especially in the higher UICC stages and particularly with respect to content and scaling of intervals of follow-up consultations (risk-adapted follow-up).

Routine follow-up is based on thorough, disease-specific history, targeted physical examination of the whole body, and mammography of the affected (in breast conserving therapy) and the contralateral breast at specific intervals, if necessary in combination with breast sonography. Follow-up treatment should be carried out for at least 10 years. Chest X-ray, abdominal sonography, and bone scan are unsuitable as screening procedures in breast cancer follow-up, but are indicated without delay when founded suspicion arises. The tumor 
markers CEA and CA15-3 in combination have a scientifically proven high predictive value, their measurement outside of scientific studies cannot, however, at present be recommended as a routine measure due to lack of evidence of an overall survival benefit. The project group proposes a prospective, nonrandomized, interdisciplinary study within the TZM in order to clarify these questions.

\section{Final Comment}

In the present 11th edition of the manual, the authors - and thus the members of the breast cancer project group in the TZM - have again succeeded in bringing the manual up to the newest level of scientific knowledge through numerous updates. Some chapters were thoroughly revised, and in some places the project group took its own stand on controversial issues. The reputation of this manual is on the one hand founded on the professional competence of the individual authors and project group members. The great strength of the project group, however, surely lies in the broad spectrum of expertise of more than 180 experts of all kinds of specialties, whose continuing interdisciplinary exchange in the course of the present revision has again led to a result which is arousing interest far beyond Munich. The manual can be ordered via the office of the TZM (Pettenkoferstraße 8a, 3. Stock, 80336 München, Germany) and can also be obtained online via tumorzentrum-muenchen.de/fileadmin/manuale/909_Manual_ Mammakarzinome.pdf, or may be purchased from bookstores. The TZM breast cancer project group is the first project group to supplement the tumor manual for physicians by issuing a complementary guide for patients based on the tumor manual which can be seen online as a test version under tumorzentrum-muenchen.de/patientenbereich/ratgeber-test.html, and can likewise be purchased in bookstores.

\section{Appendix}

Members of the Projektgruppe Mammakarzinom Tumorzentrum München

W. Abenhardt, K. Annecke, C. Anthuber, A. Artmann, S. Astner, B. Ataseven, D. Augustin, B. Aydeniz, L. Bacchus-Gerybadze, I. Bauerfeind, R.G.H. Baumeister, Th. Beck, C. Becker, M. Beer, H.J. Beyreuther, F. Bittner, P. Bojko, B. Böttcher, J. Broecker, B. Brunner, C.F. Bubb, H. Büchels, F. Busse, N. Cengic, J.C. De Waal, M. Delius, P. Dettmar, H. Dietzfelbinger, C. Difliff, N. Ditsch, F. Edler von Koch, K. Eggert, W. Eiermann, J. Engel, U. Euler, W. Flögel, M. Franek, A. Frank, T. Füger, I. Funke, S. Gabius, C. Gabka, B. Gaggermeier, M. Gassner, N. Gottschalk, D. Grab, H. Granda, D. Greif, I. Gröll de Rivera, K. Gropper, K. Gutschow, R. Haidinger, U. Hamann, C.A. Hanusch, N. Harbeck, K. Härtl, S. Hasmüller, S. Hecken, D. Hecker, M. Heindl, V. Heinemann, A.S. Heitland, H.-P. Hellemann, M. Herbst, K. Hermelink, S.H. Heywang-Köbrunner, I. Himsl, R.-T. Hoffmann, G. Hofmeister, B. Högel, D. Hölzel, C. Höß, M. Hussain, K. Imhoff, W. Janni, J. Jückstock, S. Kahlert, H. W. Kappauf, S. Keim, M. Kessler, K. Kisslinger, K.-O. Kliche, A. Kohler, J. Köhm, M. Kolben, J. Kowolik, B. Kuschel, B. Lambert, D. Lässig, R. Leibiger, M. Lenhard, H. Lindner, B. Löhrs, S.M. Lombardo, T. Lorenz, A. Lück, L. Lutz, S. Marlow, J. Martius, S. Maurer, D. Mayr, A. Meindl, P. Merx, P. Meyer, G.M. Michl, J. Mittermüller, M. Mosner, W. Müller-Holve, J. Nährig, W. Nathrath, C. Neubert, C. Neuhofer, K. Nikolajek, E. Oberlechner, W. Oettle, S. Paepke, M. Panzer, M. Patz, C. Perlet, W. Permanetter, S. Petrich, P.E. Petrides, S. Pigorsch, R. Pihusch, B. Plattner, A. Prechtl, A. Raab, G. Raab, B. Rack, G. Rauthe, B. Rieder, C. Riedner, C. Riegl,M. Riepl, D. Rjosk-Dendorfer, M. RöblMathieu, B. Röper, B. Rosskopf, S. Rupp, St. Rutke, C. Salat, D. Sattler, H. Sauer, P. Schaffer, R. Schaich, G. Schaller, D. Scheich, H.D. Schick, B. Schmalfeldt, F. Schneider, G. Schneider, R. Schröck, G. Schubert-Fritschle, H. Schuster, U. Schwarz-Boeger, M. Schwoerer, H. Sittek, K. Soltar, H. Sommer, K. Späthe, P. Stadler, J. Stamp, D. Steinfeld-Birg, H.-J. Stemmler, P. Stieber, D. Stöck1, O.J. Stoetzer, A. Strauss, C. Tsoutsoulopoulos, B. Van hove, U. Vehling-Kaiser, P. von Rottkay, E. von Tresckow, C. Waldhör, J. Walther, E. Weiß, J.H. Widmann, C. Wolf, M. Wolf, A. Wuttge-Hannig, H.-J. Wypior, C. Zirngibl.

\section{References}

1 Janni W: Manual mit Empfehlungen zur Diagnostik, Therapie und Nachsorge bei Patientinnen mit Mammakarzinom, ed 11. München, Zuckschwerdt, 2007.

2 Rosselli DT, Palli D, Cariddi A, Ciatto S, Pacini P, Distante V: Intensive diagnostic follow-up after treatment of primary breast cancer. A randomized trial. National Research Council Project on Breast Cancer follow-up. JAMA 1994;271:1593-1597.

3 GIVIO T: Impact of follow-up testing on survival and health-related quality of life in breast cancer patients. A multicenter randomized controlled trial. The GIVIO Investigators. JAMA 1994;271:15871592.
4 Rojas MP, Telaro E, Russo A, Moschetti I, Coe L, Fossati R, Palli D, del Roselli TM, Liberati A: Follow-up strategies for women treated for early breast cancer. Cochrane Database Syst Rev 2005; CD001768.

5 Engel J, Beinert T, Delius M, Hölzel D, SchubertFritschle G: Epidemiologie; in Janni W (ed): Manual mit Empfehlungen zur Diagnostik, Therapie und Nachsorge bei Patientinnen mit Mammakarzinom. München, Zuckschwerdt, 2007, pp 1-11.

6 Wolf C, Artmann A, de Waal J, Paepke S: Mammakarzinom-Prävention; in Janni W (ed): Manual mit Empfehlungen zur Diagnostik, Therapie und Nachsorge bei Patientinnen mit Mammakarzinom. München, Zuckschwerdt, 2007, pp 12-29.
7 Abenhardt W, Artmann A, Astner S, Bastert G, Bojko P, de Waal J, Eiermann W, Engel J, Heinemann V, Janni W, Kessler M, Lutz L, Rauthe G, Sommer H, Stieber P, Wolf M: Nachsorge; in Janni W (ed): Manual mit Empfehlungen zur Diagnostik, Therapie und Nachsorge bei Patientinnen mit Mammakarzinom. München, Zuckschwerdt, 2007, pp 164-179. 